\title{
ARTICLE
}

Received 10 Jul 2012 | Accepted 7 Dec 2012 | Published 15 Jan 2013

DOI: $10.1038 /$ ncomms2364

OPEN

\section{Signalling properties of inorganic polyphosphate in the mammalian brain}

Kira M. Holmström, Nephtali Marina ${ }^{2}$, Artyom Y. Baev ${ }^{1}$, Nicholas W. Wood ${ }^{1}$, Alexander V. Gourine ${ }^{2, \star}$ \& Andrey Y. Abramov ${ }^{1, \star}$

Inorganic polyphosphate is known to be present in the mammalian brain at micromolar concentrations. Here we show that polyphosphate may act as a gliotransmitter, mediating communication between astrocytes. It is released by astrocytes in a calcium-dependent manner and signals to neighbouring astrocytes through $\mathrm{P} 2 \mathrm{Y}_{1}$ purinergic receptors, activation of phospholipase $\mathrm{C}$ and release of calcium from the intracellular stores. In primary neuroglial cultures, application of polyP triggers release of endogenous polyphosphate from astrocytes while neurons take it up. In vivo, central actions of polyphosphate at the level of the brainstem include profound increases in key homeostatic physiological activities, such as breathing, central sympathetic outflow and the arterial blood pressure. Together, these results suggest a role for polyphosphate as a mediator of astroglial signal transmission in the mammalian brain.

\footnotetext{
${ }^{1}$ Department of Molecular Neuroscience, UCL Institute of Neurology, London WC1N 3BG, UK. ${ }^{2}$ Department of Neuroscience, Physiology and Pharmacology University College London, London WC1E 6BT, UK. * Joint senior authors. Correspondence and requests for materials should be addressed to A.V.G. (email: a.gourine@ucl.ac.uk) or to A.Y.A. (email: a.abramov@ucl.ac.uk).
} 
B rain function relies on fast and effective communication between cells, and molecules of diverse origin and chemical structure (amino acids, monoamines, gases, purines and others) have been shown to mediate signal transmission within and between interconnected neuronal and glial networks. Inorganic polyphosphates (polyPs) are linear polymers of orthophosphate residues linked by phosphoanhydride bonds that have been identified in a variety of mammalian tissues, including the central nervous system $(\mathrm{CNS} ; 25-120 \mu \mathrm{M})^{1,2}$. For many years, polyP was thought to be a 'fossil' molecule with no clear function in higher organisms, as no specific mammalian enzymes responsible for synthesis and degradation of polyP were identified. Recently, we showed that polyP can be produced by mammalian mitochondria ${ }^{3}$ and has an important role in the mechanisms underlying $\mathrm{Ca}^{2}{ }^{+}$-dependent cell death ${ }^{4}$. PolyP was also identified as one of the key modulators of platelet-mediated pro-inflammatory and pro-coagulant disorders ${ }^{5}$. Furthermore, polyP has been shown to modulate the activities of TRPA1 and TRPM8 channels ${ }^{6,7}$, suggesting that it may be involved in neuronal signalling.

Here we demonstrate previously unappreciated signalling properties of polyP in the mammalian CNS. The data obtained suggest that polyP acts as a gliotransmitter through astroglial purinergic receptors, more specifically $\mathrm{P}_{2} \mathrm{Y}_{1}$, leading to activation of phospholipase $\mathrm{C}$ (PLC) and release of $\mathrm{Ca}^{2}+$ from the internal stores. Application of polyP to primary neuroglial cultures initiates further release of polyP from astrocytes while neurons take it up. This is dependent on $\mathrm{Ca}^{2+}$, as the $\mathrm{Ca}^{2+}$ ionophore ionomycin also releases polyP. In vivo, central actions of polyP are consistent with astroglial activation, and at the level of the brainstem include profound increases in breathing, central sympathetic outflow and the arterial blood pressure.

\section{Results}

PolyP induces a calcium signal in cultured astrocytes. As activation of brain cells is marked by increases in intracellular $\mathrm{Ca}^{2+}\left(\left[\mathrm{Ca}^{2+}\right]_{\mathrm{c}}\right)$, we determined whether application of polyP, at concentrations which have been found in the mammalian brain $(0.1-100 \mu \mathrm{M})^{1}$, has an effect on $\left[\mathrm{Ca}^{2+}\right]_{\mathrm{c}}$ in cultured neurons and astrocytes. In the rat neuroglial cultures, the majority of astrocytes and a small fraction of neurons responded with increases in $\left[\mathrm{Ca}^{2+}\right]_{c}$, following application of short (S; Supplementary Fig. S1a), medium (M; Fig. 1a) or long (L; Supplementary Fig. S1b) polyP $(14,60,130$ phosphates, respectively). There were no significant differences in the amplitudes of $\mathrm{Ca}^{2}+$ signals evoked in astrocytes by polyP of different lengths. However, the number of astrocytes that responded to polyP varied from 19 to $74 \%$, depending on the concentration and length of polyP applied (Supplementary Fig. S1c-e), whereas only a small fraction (3\%, $n=120)$ of neurons responded even to high concentrations $(50 \mu \mathrm{M})$ of polyP (Fig. 1b). These polyP-evoked responses were observed in the midbrain, hippocampal, as well as cortical cultures. For consistency, all subsequent experiments were performed using $\mathrm{M}$-polyP at a concentration of $50 \mu \mathrm{M}$, whereas the results have been independently confirmed using L-polyP. Further characterization of polyP-induced signalling indicated that the recovery time of the evoked $\mathrm{Ca}^{2+}$ transients is in the range of $700-1,000 \mathrm{~s}$, as assessed by repeated applications of polyP to the same preparation (Supplementary Fig. S1f-h). Consistent with these results, we found that the responses originate from $\mathrm{Ca}^{2+}$ recruitment from the internal stores, as removal of extracellular $\mathrm{Ca}^{2+}\left(\mathrm{Ca}^{2+}\right.$-free media containing $0.5 \mathrm{mM}$ EGTA; $n=279$; Fig. 1c) did not block polyP-evoked responses in astrocytes. This was confirmed by complete inhibition of polyP-induced $\mathrm{Ca}^{2}$ signal after emptying reticulum $\mathrm{Ca}^{2+}$ stores $(1 \mu \mathrm{M}$ thapsigargin-induced SERCA inhibition; $n=101$; Fig. 1d). The PLC inhibitor U73122 (5 $\mu \mathrm{M})$ also completely blocked polyP-induced $\mathrm{Ca}^{2}+$ responses in astrocytes (Fig. 1e,f; $n=739$ ), suggesting that PLC is recruited, leading to $\mathrm{IP}_{3}$ generation and mobilization of internal $\mathrm{Ca}^{2+}$ stores. Upstream of PLC activation, we were able to identify the receptor mediating the observed actions of polyP. Blockade of purinergic receptors using the broad spectrum P2 receptor antagonist suramin $(500 \mu \mathrm{M} ; n=245$; Fig. 1f) was found to completely abolish polyP-evoked $\left[\mathrm{Ca}^{2}+\right]_{c}$ responses in cultured astrocytes.

PolyP-induced calcium signalling by $\mathrm{P}_{2} \mathrm{Y}_{1}$ receptor activation. To identify the specific $\mathrm{P} 2$ receptor through which polyP exerts its action, we tested several more selective P2 receptor antagonists. As polyP-evoked increases in intracellular $\left[\mathrm{Ca}^{2+}\right]_{c}$ originate from the endoplasmic reticulum, the ionotropic ( $\mathrm{P} 2 \mathrm{X})$ purinoreceptors could be ruled out. Selective antagonists of $\mathrm{P} 2 \mathrm{Y}_{1}, \mathrm{P} 2 \mathrm{Y}_{6}, \mathrm{P} 2 \mathrm{Y}_{11}$ (MRS2279 (ref. 8) (500 nM-50 $\mu \mathrm{M})$, MRS2578 (refs 9,10) $(10 \mu \mathrm{M})$ and NF340 (ref. 10$)(10 \mu \mathrm{M})$, respectively) were applied before testing the effects of polyP. MRS2578 and NF340 were ineffective $(n=109$ and $n=295$, respectively (Fig. 1f)); however, blockade of polyP-induced $\mathrm{Ca}^{2}+$ responses with MRS2279 suggested that activation of $\mathrm{P}_{2} \mathrm{Y}_{1}$ receptors mediates polyP-induced effects. The number of cells that responded to application of polyP was greatly suppressed in cultures pretreated with MRS2279 (50 $\mu \mathrm{M} n=803$; Fig. 1f, $5 \mu \mathrm{M}(n=472)$ and $500 \mathrm{nM}(n=172)$; Supplementary Fig. S2a). Knockdown of the $\mathrm{P}_{2} \mathrm{Y}_{1}$ receptor using specific short hairpin RNA (shRNA) led to a reduced expression of the targeted protein (Supplementary Fig. S2b,c) as compared with a non-targeting shRNA (Scr). The loss of $\mathrm{P}_{2} \mathrm{Y}_{1}$ receptor expression resulted in a significant reduction in the number of cells that responded to application of polyP ( $\mathrm{P}_{2} \mathrm{Y}_{1}, n=201$; Scr, $n=51$; Fig. $\left.1 \mathrm{~g}\right)$. PolyP-evoked responses do not appear to be mediated by prior release of ATP, as pre-treatment of cultures with ATP-degrading enzymes hexokinase $\left(25 \mathrm{U} \mathrm{ml}^{-1}\right)$ or apyrase $\left(25 \mathrm{Uml}^{-1} ; n=96\right.$ and $n=101$, respectively; Fig. $1 \mathrm{f}$ ) had no effect on the numbers of responding cells and amplitudes of the evoked $\mathrm{Ca}^{2}+$ transients (Fig. 1h). Furthermore, ATP $(100 \mu \mathrm{M})$, but not polyP-evoked $\mathrm{Ca}^{2}+$ responses, were effectively blocked by apyrase (Supplementary Fig. S2d), confirming the efficacy of this approach in blocking ATP actions. Collectively, these data suggest that polyP may act on purinergic $\mathrm{P}_{2} \mathrm{Y}_{1}$ receptors, leading to activation of PLC and recruitment of $\mathrm{Ca}^{2}+$ from the internal stores.

PolyP evokes release of endogenous polyP. PolyP can be visualized in living cells after binding to the fluorescent dye $\left(4^{\prime}, 6 \text {-diamidino-2-phenylindole) DAPI (polyP-DAPI }\right)^{5,11}$. Astrocytes loaded with DAPI show an uneven polyP distribution in different cellular compartments-the nucleus, lysosomes, mitochondria and cytoplasmic vesicle-like structures (Fig. 2a; Supplementary Fig. S3a; see also refs 3,4,11,12). Application of polyP to DAPI-loaded neuroglial cultures resulted in an immediate loss of vesicular polyP-DAPI staining in astrocytes and a concomitant increase in extracellular polyP (astrocytes $n=22$; Fig. 2a-c), indicating release of polyP. This was accompanied by an increase in polyP-DAPI fluorescence in neurons (increase in fluorescence by $63.6 \pm 4.3 \%$ in neurons, $n=32$ compared with a decrease in astrocytes by $46.4 \pm 3.9 \%, n=39$ ), suggesting that polyP is taken up by neurons (Fig. 2d,e). As the plasma membrane is impermeable to polyP, these observations suggest that polyP is cleared from the extracellular space by neuronal uptake (via an unknown 

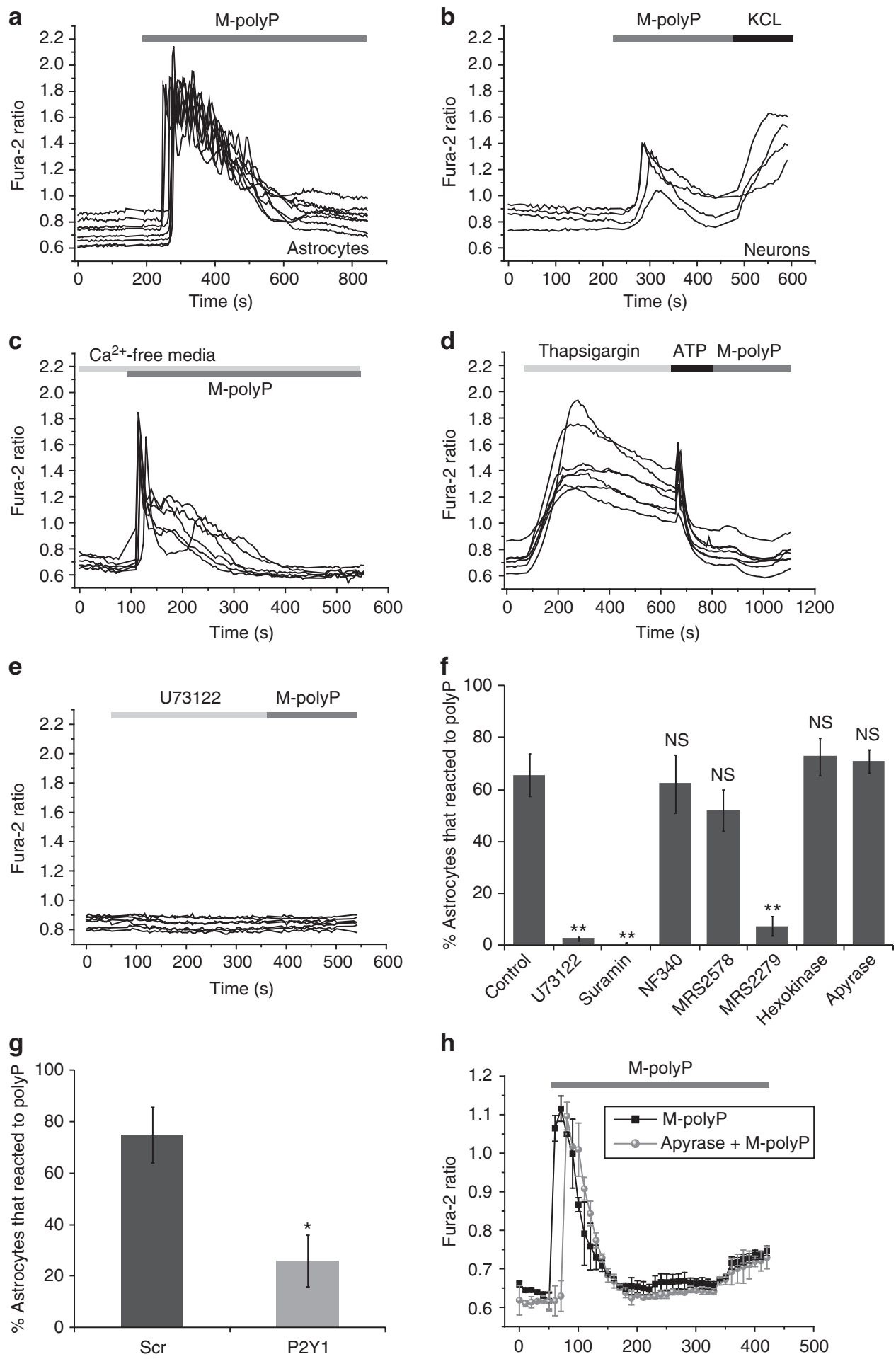

h

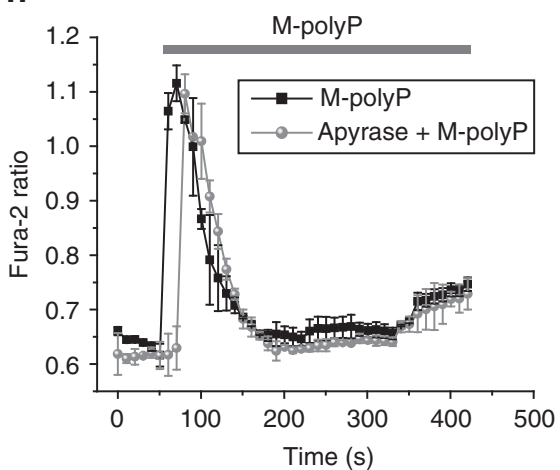

Figure 1 | PolyP induces $\mathbf{C a}^{2+}$ responses in neurons and astrocytes. Medium polyP $(50 \mu \mathrm{M})$ induces $\left[\mathrm{Ca}^{2+}\right]_{\mathrm{C}}$ changes in hippocampal astrocytes (a) and neurons (b) as seen by an increase in the ratio of the $\mathrm{Ca}^{2+}$ dye Fura-2. $\mathrm{KCl}(50 \mathrm{mM})$ was added at the end of the experiment for cellular (neuronal) identification. (c) Removal of external $\mathrm{Ca}^{2+}\left(\mathrm{Ca}^{2+}\right.$-free medium with $0.5 \mathrm{mM}$ EDTA $)$ does not abolish polyP-induced $\mathrm{Ca}^{2+}$ responses in astrocytes in response to $50 \mu \mathrm{M} \mathrm{M}$-polyP. (d) Depletion of intracellular $\mathrm{Ca}^{2+}$ stores with thapsigargin $(1 \mu \mathrm{M})$ and ATP $(100 \mu \mathrm{M})$ abolishes M-polyP $(50 \mu \mathrm{M})$-induced Ca ${ }^{2+}$ responses in astrocytes.

(e) M-polyP $(50 \mu \mathrm{M})$-induced $\left[\mathrm{Ca}^{2+}\right]_{c}$ responses are inhibited in the presence of the PLC inhibitor U73122 $(5 \mu \mathrm{M})$. Shown are representative traces from at least three independent experiments. (f) PLC inhibitor U73122, P2 receptor antagonist suramin ( $500 \mu \mathrm{M})$, and specific P2Y $\mathrm{Y}_{1}$ receptor antagonist MRS2279 (50 $\left.\mu \mathrm{M}\right)$ blocked the polyP-induced $\left[\mathrm{Ca}^{2+}\right]_{c}$ responses, whereas the ATP-degrading enzymes hexokinase and apyrase (each $25 \mathrm{Uml}^{-1}$ ) and the specific $\mathrm{P} 2 \mathrm{Y}_{6}, \mathrm{P} 2 \mathrm{Y}_{11}$ receptor inhibitors (MRS2578 $(10 \mu \mathrm{M})$ and NF340 $(10 \mu \mathrm{M})$, respectively) had no effect. All experiments were performed using $50 \mu \mathrm{M}$ M-polyP. Error bars represent s.e.m., $n>100$ cells for each condition, ${ }^{\star \star} \mathrm{P}<0.005$, N.S., not significant. (g) Knockdown of the $\mathrm{P} 2 \mathrm{Y}_{1}$ receptor using shRNA suppressed the polyP-induced $\mathrm{Ca}^{2+}$ signal (compared with a scrambled control, Scr). Error bars represent s.e.m., $n=201$ for $P 2 Y_{1}$ and $n=51$ for $\mathrm{Scr},{ }^{\star} P<0.05$. (h) Pre-incubation of cells with apyrase $\left(25 \mathrm{U} \mathrm{ml}^{-1}\right)$ did not affect the amplitude of M-polyP (50 $\mu \mathrm{M})$-induced $\mathrm{Ca}^{2+}$ signal. Student's $t$-test was used to asses statistical significance. 
a

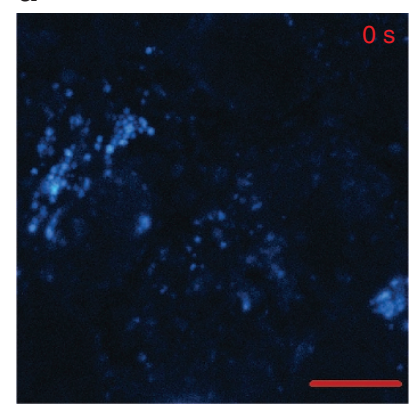

b
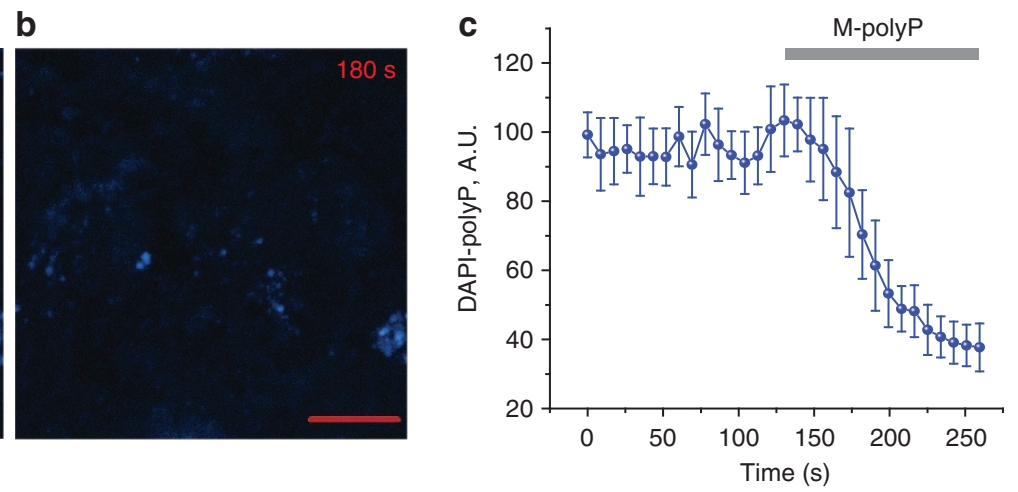

d

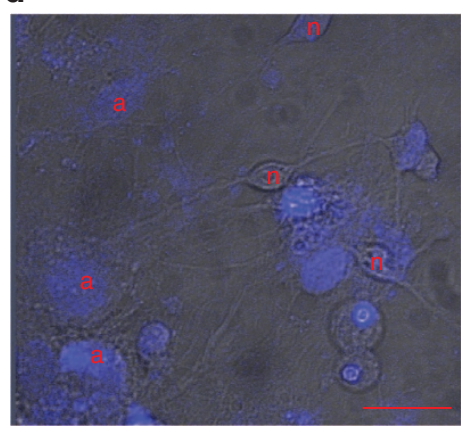

e

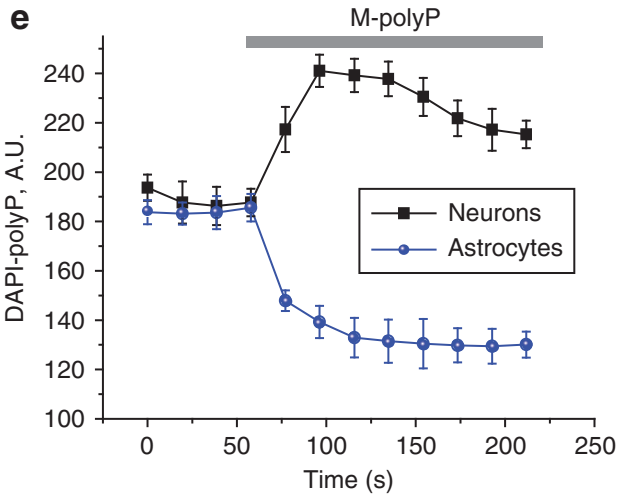

h

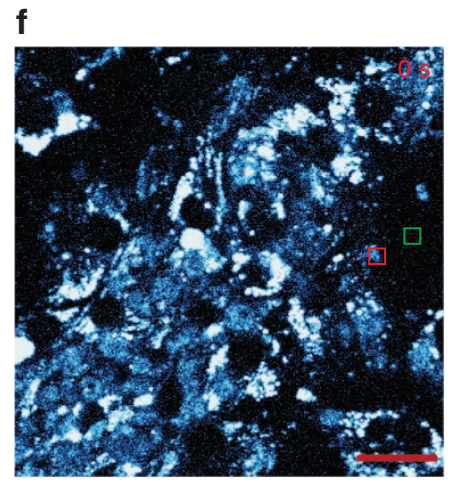

g
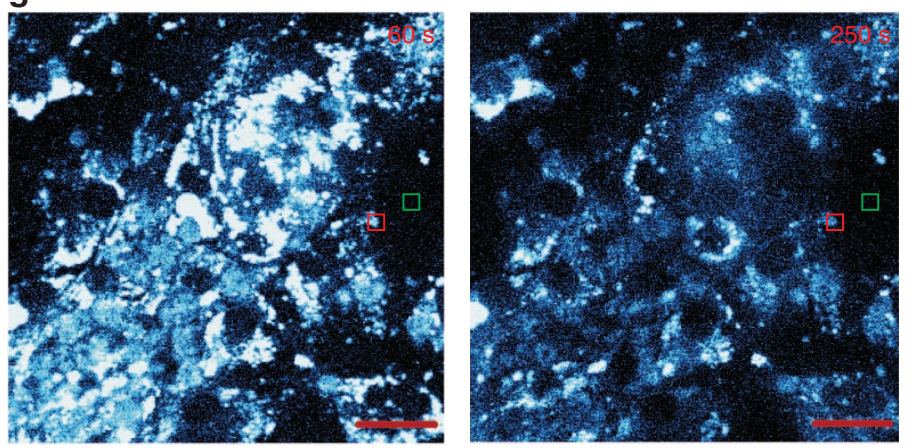

i

j

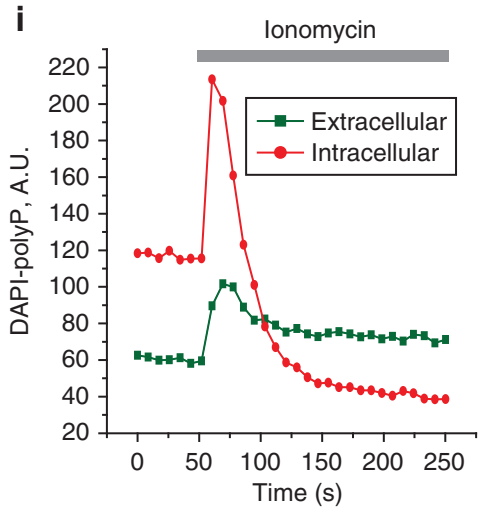

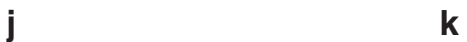

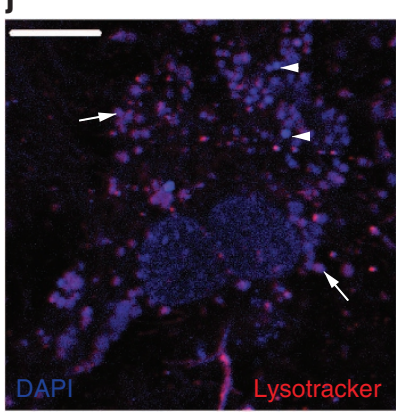

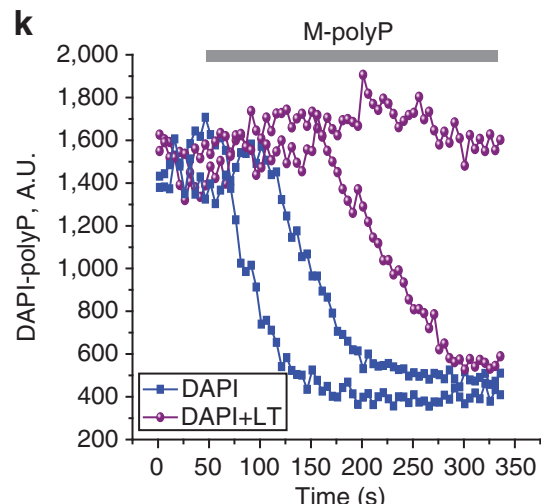

Figure 2 | Uptake and release of polyP in primary neuroglial co-cultures. PolyP can be detected in vesicle-like structures in astrocytes using DAPI (DAPI-polyP) (a). Application of M-polyP $(50 \mu \mathrm{M})$ to DAPI-loaded neuroglial cultures induces release of polyP as seen by a decrease in intracellular vesicular DAPI-polyP (a-c). Error bars represent s.e.m. $n=93$ cells. Shown are representative images from two time points and the mean trace. Scale bar, $10 \mu \mathrm{m}$. PolyP released from astrocytes (a) upon stimulation with M-polyP $(50 \mu \mathrm{M})$ is taken up by neurons $(n)$ as seen by DAPI-polyP (d). (d) Bright-field image combined with DAPI-polyP staining (blue). Scale bar, $20 \mu \mathrm{m}$. (e) Representative mean traces from neurons and astrocytes. Error bars represent s.e.m. $n=54$ neurons and $n=61$ astrocytes. $(\mathbf{f}-\mathbf{i})$ Application of ionomycin $(5 \mu \mathrm{M})$ induces release of vesicular polyP from cortical astrocytes. Shown are representative images from three time points $(0,60,250 \mathrm{~s})(\mathbf{f}-\mathbf{h})$ and the corresponding traces (i). (j) Loading of neuroglial cultures with DAPI and Lysotracker (LT) simultaneously indicates partial colocalization of DAPI-polyP with lysosomes (arrows), whereas other DAPI-polyP vesicles do not stain with LT (arrow heads). Scale bar, $10 \mu \mathrm{m}$. (k) PolyP is released from a proportion of LT and DAPI co-stained vesicles upon addition of $50 \mu \mathrm{M} \mathrm{M}$-polyP. 
transporter mechanism) and indicate polyP-evoked polyP release. Interestingly, polyP release was also evoked when the $\mathrm{Ca}^{2+}$ ionophore ionomycin was applied $(n=29$; Fig. $2 \mathrm{f}-\mathrm{i})$, suggesting that the mechanism of polyP release is $\mathrm{Ca}^{2}+$-dependent. PolyPand ionomycin-evoked polyP releases were confirmed with TBEUrea gel electrophoresis and staining with DAPI (Supplementary Fig. S3b).

Interestingly, polyP has been found in lysosomes ${ }^{12}$. We found partial colocalization of polyP-DAPI with the lysosomal marker LysoTracker (Fig. 2j), which selectively labels lysosomes in cultured astrocytes ${ }^{13}$. Stimulation of cells with exogenous polyP induces release of DAPI-polyP from some but not all lysosomes, although predominantly polyP is released from non-lysosomal vesicle-like compartments (Fig. 2k). These data indicate that astrocytes can release polyP via $\mathrm{Ca}^{2+}$-dependent exocytotic mechanism.

$\mathrm{Ca}^{2+}$-dependent release of endogenous polyP. As an increase in $\left[\mathrm{Ca}^{2+}\right]_{\mathrm{c}}$ induces release of polyP, we next determined whether $\mathrm{Ca}^{2}+$ excitation of astrocytes results in a release of endogenous polyP and polyP-mediated activation of neighbouring cells. We used caged $\mathrm{Ca}^{2}+$ (np-EGTA) and flash photolysis to evoke an increase in intracellular $\mathrm{Ca}^{2}+$ in an individual cell (flashed). $\mathrm{Ca}^{2+}$ uncaging in a single astrocyte triggered an increase in intracellular $\left[\mathrm{Ca}^{2+}\right]_{c}$ in neighbouring (non-flashed) astrocytes (Fig. 3c), even in the presence of apyrase $\left(25 \mathrm{U} \mathrm{ml}^{-1}\right.$; Fig. 3a,b) and inhibitors of either ionotropic or metabotropic glutamate receptors, including CNQX $(20 \mu \mathrm{M} ; n=5$ experiments), MK-801 $(10 \mu \mathrm{M} ; n=9$ experiments) or (S)-MCPG $(50 \mu \mathrm{M} ; n=6$ experiments). However, suramin $(500 \mu \mathrm{M})$ or MRS2279 (5 and $50 \mu \mathrm{M}$; Fig. 3d and Supplementary Fig. S2e) blocked $\mathrm{Ca}^{2+}$ responses in neighbouring cells, suggesting that $\mathrm{Ca}^{2+}$-dependent release of
polyP from astrocytes induces a $\mathrm{Ca}^{2+}$ signal in neighbouring cells through activation of $\mathrm{P}_{2} \mathrm{Y}_{1}$ receptors.

PolyP evokes profound cardiorespiratory responses in vivo. Finally, we established the effects of polyP in vivo. Using anaesthetized and artificially ventilated rats, we found that application of polyP to the chemosensory areas located on the ventral surface of the brainstem evokes profound increases in key cardiorespiratory variables-breathing (by $241 \pm 37 \% ; P=0.030 ; n=6$ ), central sympathetic outflow (by $101 \pm 20 \% ; P=0.011 ; n=6$ ),

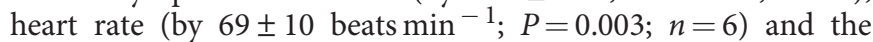
arterial blood pressure (by $41 \pm 5 \mathrm{~mm} \mathrm{Hg} ; P=0.002 ; n=6$; Fig. $4 \mathrm{a}, \mathrm{b})$. These effects of polyP lasted for $31 \pm 4 \min (n=6)$. MRS2279 $(50 \mu \mathrm{M})$ or broad spectrum P2 receptor antagonist PPADS (pyridoxal-phosphate-6-azophenyl-2',4'-disulphonate; $100 \mu \mathrm{M})$ applied on the ventral surface of the brainstem $5 \mathrm{~min}$ before polyP had no effect on resting level of cardiorespiratory activity (Supplementary Fig. S4), but dramatically reduced the magnitude of polyP-evoked responses (Fig. 4b,c). This is consistent with the effects of polyP on the brainstem subpial astrocytes and glia limitants capable of driving these changes in response to physiological stimulation (such as decreased $\mathrm{pH})^{14}$. These data indicate that the effects of exogenously applied polyP on respiratory and cardiovascular activities are remarkably similar to that of another notable gliotransmitter-ATP ${ }^{15}$.

\section{Discussion}

In summary, our data show that polyP triggers strong activation (increases in intracellular $\mathrm{Ca}^{2+}$ ) of the majority of astrocytes, irrespective of the brain region examined and of a small proportion of CNS neurons. This is consistent with the data showing that polyP signals via activation of P2Y receptors, more a

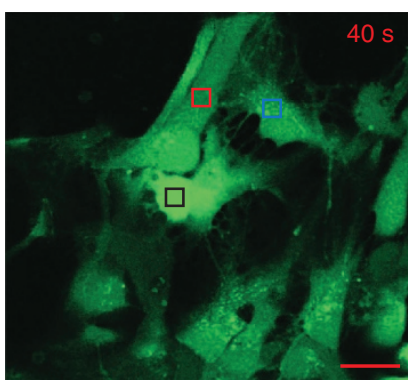

C

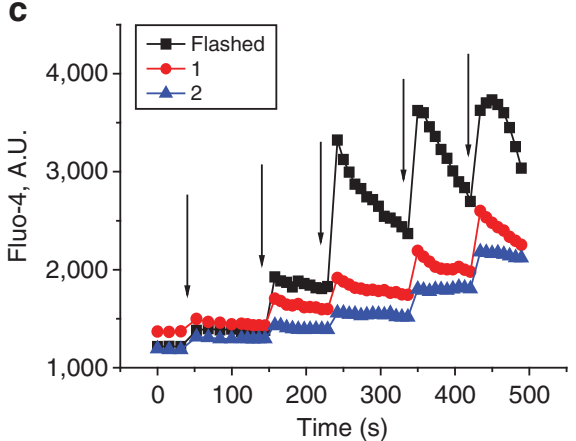

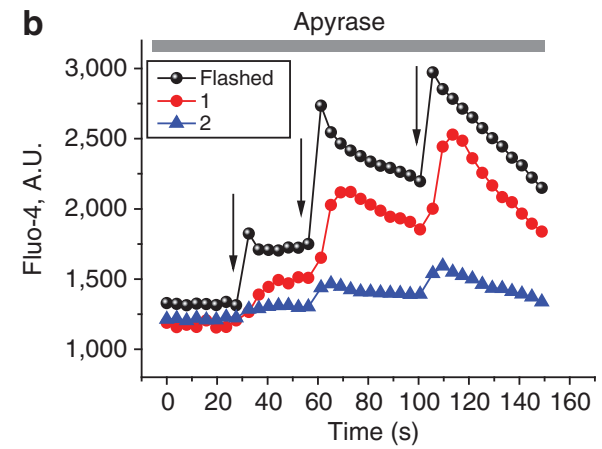

d

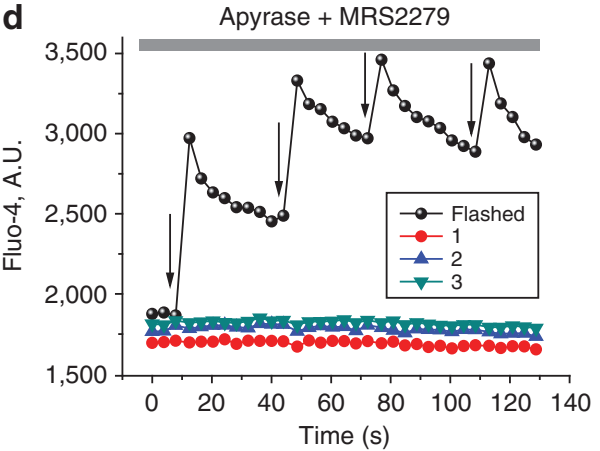

Figure 3 / $\mathbf{C a}^{2}+$-induced polyP release. Uncaging of $\mathrm{Ca}^{2+}$ by ultraviolet flash (depicted by black arrows and a black square and trace) in a single cultured astrocyte induces $\mathrm{Ca}^{2+}$ signal in neighbouring cells in the presence of apyrase $\left(25 \mathrm{U} \mathrm{ml}^{-1}\right.$; red and blue squares and traces) (a,b). Scale bar, $20 \mu \mathrm{m}$. (c) Removal of apyrase from the medium had no effect on the amplitude of the induced $\mathrm{Ca}^{2+}$ signal (black arrows indicate time of the flash). (d) The transmission of the signal can be blocked by inhibition of the $\mathrm{P}_{2} \mathrm{Y}_{1}$ receptors with MRS2279 $(50 \mu \mathrm{M})$. 
a M-polyP
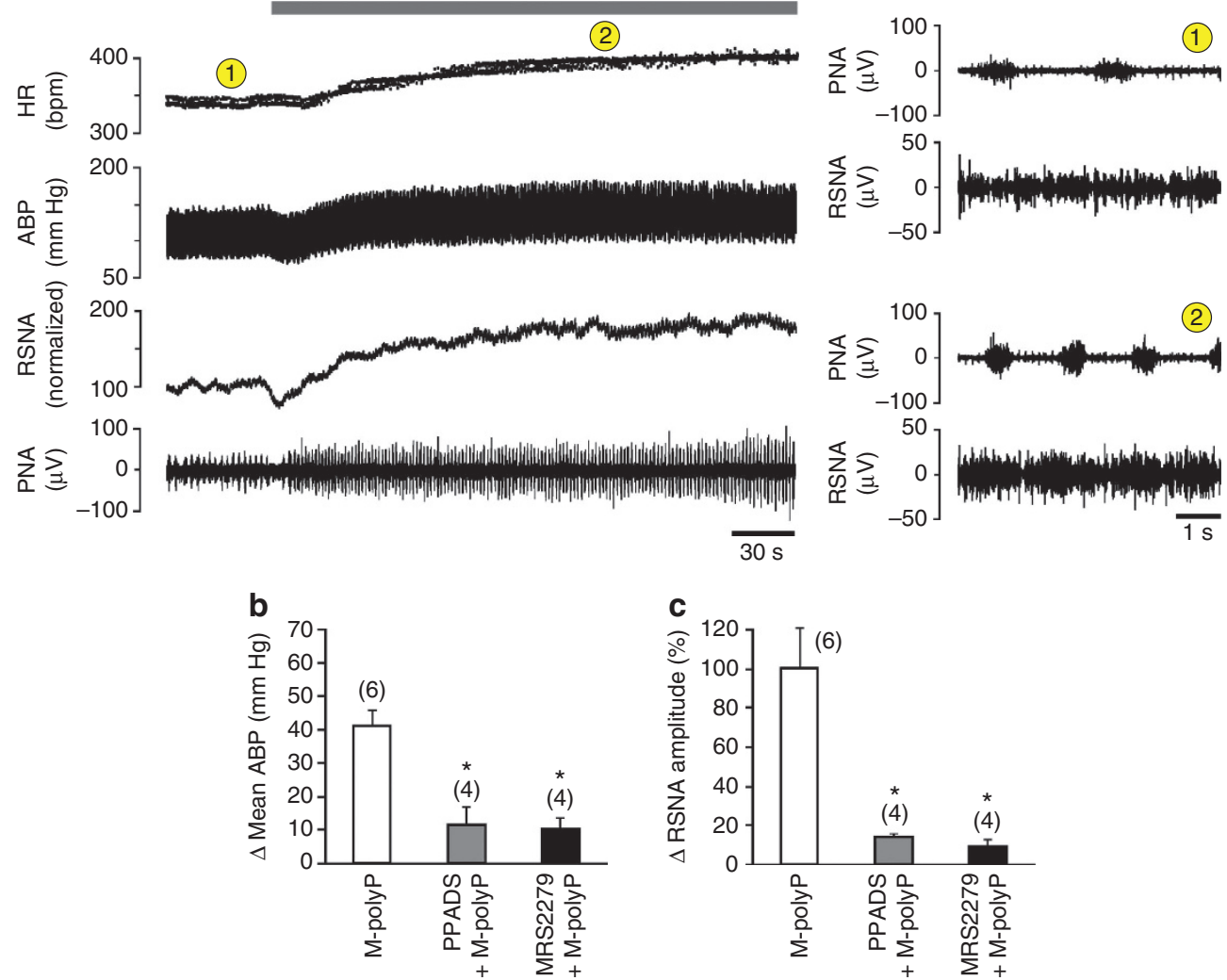

Figure 4 | Effects of polyP in vivo. Application of M-polyP $(50 \mu \mathrm{M})$ to the ventral surface of the brainstem increases heart rate (HR), arterial blood pressure (ABP), renal sympathetic nerve activity (RSNA) and phrenic nerve activity (PNA) (a). Expanded traces of PNA and RSNA on the right depict the activities before and after application of polyP. Time points are indicated by numbers (1) and (2) on the time-condensed trace on the left. The effects of M-polyP on the ABP (b) and RSNA (c) in vivo are blocked by pre-treatment with P2 receptor antagonists PPADS (100 $\mu$ M) or MRS2279 (50 $\mu$ M). Values are means \pm s.e.m. Numbers in parentheses indicate sample sizes. ${ }^{\star} P<0.01$ compared with the effect of M-polyP applied alone (ANOVA followed by Tukey-Kramer's post hoc test).

specifically $\mathrm{P}_{2} \mathrm{Y}_{1}$, which are found to be expressed predominantly by astroglia ${ }^{16}$. Interestingly, $\mathrm{P}_{2} \mathrm{Y}_{1}$ receptors are known to be activated by a diverse array of molecules, including ADP and ATP, as well as by diadenosine polyP, a molecule containing two adenosines and up to seven phosphate groups ${ }^{17}$. Furthermore, specific residues of the $\mathrm{P}_{2} \mathrm{Y}_{1}$ receptor complex are known to interact with phosphate groups ${ }^{18}$.

$\mathrm{P}_{2} \mathrm{Y}_{1}$ receptors are not only expressed in the CNS but also in many other tissues, including smooth muscle, bone and platelets ${ }^{16}$. Interestingly, polyP has been shown to be released by activated platelets ${ }^{5}$. Whether polyP-induced polyP release triggered via activation of $\mathrm{P} 2 \mathrm{Y}_{1}$ receptors is a common mechanism remains to be determined. In neuroglial cultures, activation of astrocytes leads to the release of polyP, which is cleared from the extracellular space by neuronal uptake. Whether this is only lysosomal release, as our data suggest, or also occurs via vesicular mechanisms which similarly has been implicated in the release of gliotransmitters (such as ATP) from astrocytes ${ }^{19}$, remains to be seen. It is also possible that other transmitters

such as ATP and diadenosine polyP are being released simultaneously with polyP. Furthermore, there are probably other $\mathrm{P} 2 \mathrm{Y}$ receptors to which polyP can bind, as loss of $\mathrm{P}_{2} \mathrm{Y}_{1}$ activity does not fully block polyP-induced $\mathrm{Ca}^{2}+$ signalling. The actions of polyP on the brainstem respiratory and autonomic circuits stimulate breathing, increase sympathetic outflow and raise arterial blood pressure (in a $\mathrm{P}_{2} \mathrm{Y}_{1}$ receptor-dependent manner), demonstrating potential functional significance of polyP-mediated signalling in vivo. Interestingly, although the polyP-mediated effects are similar to those of $\mathrm{ATP}^{14}$ they are not dependent on ATP, suggesting that ATP and polyP may have common downstream targets. These data suggest that activated astrocytes in the mammalian CNS are capable of utilizing polyP as a gliotransmitter, which may have an important role in the control of vital behaviours in which astroglia are implicated.

\section{Methods}

Cell culture. Mixed cultures of hippocampal, cortical or midbrain neurons and glial cells were prepared as described previously ${ }^{20}$, with modifications, from Sprague-Dawley rat pups 3 days postpartum (UCL breeding colony). Hippocampi, cortex and midbrain were removed into ice-cold HEPES buffered salt solution $\left(\mathrm{Ca}^{2+}, \mathrm{Mg}^{2+}\right.$-free; Gibco-Invitrogen, Paisley, UK). The tissue was minced and trypsinized $\left(0.25 \%\right.$ for $15 \mathrm{~min}$ at $\left.37^{\circ} \mathrm{C}\right)$, triturated and plated on poly-D-lysinecoated coverslips and cultured in neurobasal A medium (Gibco-Invitrogen) supplemented with B-27 (Gibco-Invitrogen) and $2 \mathrm{mM}$ L-glutamine. Cultures were maintained at $37^{\circ} \mathrm{C}$ in a humidified atmosphere of $5 \% \mathrm{CO}_{2}$ and $95 \%$ air, fed once a week and maintained for a minimum of 12 days before experimental use, to ensure the expression of glutamate and other receptors. Neurons were easily distinguishable from glia: they appeared phase bright, had smooth rounded somata and distinct processes, and lay just above the focal plane of the glial layer. Cells were used at 14-21days in vitro.

A lentiviral pGIPZ shRNA vector encoding shRNA targeting $\mathrm{P}_{2} \mathrm{Y}_{1}$ receptor and a negative, non-targeting shRNA control (scr) vector, both of which also encode green fluorescent protein as a reporter protein, were obtained from a commercial provider (Thermo Fisher). With HEK 293T cells, the pGIPZ and negative shRNA vectors were packaged into a lentivirus using a three plasmid transfection 
procedure $^{21}$. Primary neuroglial cultures were then transduced with the packaged pGIPZ shRNA lentivirus. In brief, cells on one 6- $\mathrm{cm}$ dish were incubated in $2 \mathrm{ml}$ DMEM containing the virus for $4 \mathrm{~h}$. After $4 \mathrm{~h}$, the medium was exchanged for normal neurobasal A medium, and the cultures were incubated for an additional $72 \mathrm{~h}$. Transduction efficiency was estimated to be between $30-80 \%$ by direct visualization of green fluorescent protein expression.

Imaging $\left[\mathrm{Ca}^{2+}\right]_{\mathbf{c}}$ and polyP. Primary neurons and astrocytes were loaded for $30 \mathrm{~min}$ at room temperature with $5 \mu \mathrm{M}$ fluo- $4,5 \mu \mathrm{M}$ fura-2 $\mathrm{AM}, 5 \mu \mathrm{M}$ lysotracker Red DND-99 or 0.5 $\mu$ M DAPI (Molecular Probes, Eugene, OR), and 0.005\% Pluronic in a HEPES buffered salt solution composed (in $\mathrm{mM}$ ) $156 \mathrm{NaCl}, 3 \mathrm{KCl}, 2$ $\mathrm{MgSO}_{4}, 1.25 \mathrm{KH}_{2} \mathrm{PO}_{4}, 2 \mathrm{CaCl}_{2}, 10$ glucose and 10 HEPES, pH adjusted to 7.35 with $\mathrm{NaOH} . \mathrm{Ca}^{2+}$-free medium contained $0.5 \mathrm{mM}$ EGTA and no $\mathrm{Ca}^{2+}$. PolyP standards (sodium salt with polyP content of $60 \%$ ) were provided by Dr T Shiba (Regenetiss, Inc., Japan).

Fluorescent $\mathrm{Ca}^{2}+$ measurements using fura- 2 were obtained on an epifluorescence inverted microscope equipped with a X20 fluorite objective. Changes in $\left[\mathrm{Ca}^{2+}\right]_{\mathrm{c}}$ were monitored in single cells using excitation light provided by a Xenon arc lamp, the beam passing monochromator at 340,380 nm (Cairn Research, Kent, UK). Emitted fluorescence light was reflected through a 515-nm long pass filter to a cooled CCD camera (Retiga, QImaging, Canada) and digitized to 12 bit resolution. All imaging data were collected and analysed using software from Andor (Belfast, UK). The fura-2 data have not been calibrated in terms of $\left[\mathrm{Ca}^{2+}\right]_{c}$ because of the uncertainty arising from the use of different calibration techniques. When inhibitors were used, control recordings were first performed in the absence of the antagonist.

Confocal images in combination with flash photolysis were obtained using a Zeiss 510 UV-vis CLSM equipped with a META detection system and a X40 oil immersion objective. For flash photolysis experiments, caged $\mathrm{Ca}^{2+}, 10 \mu \mathrm{M}$ $o$-nitrophenyl EGTA, AM (NP-EGTA, AM) was loaded at the same time as fluo-4 (ref. 22). Each ultraviolet flash was targeting a single cell. The 488-nm Argon laser line was used to excite fluo-4, which was measured at $505-550 \mathrm{~nm}$. Illumination intensity was kept to a minimum (at $0.1-0.2 \%$ of laser output) to avoid phototoxicity and the pinhole set to give an optical slice of $\sim 2 \mu \mathrm{m}$.

Confocal images of DAPI-polyP and Lysotracker staining were obtained using a Zeiss 710 LSM equipped with a META detection system and a X40 oil immersion objective. DAPI emission spectra were measured using $405 \mathrm{~nm}$ laser for excitation. The specific DAPI-polyP emission signal was measured above $550 \mathrm{~nm}$, using the Zeiss 'META' system and presented as arbitrary units (A.U. ${ }^{4,11}$. A separation of the DAPI-DNA and DAPI-polyP signal is shown in Supplementary Figure S2a. Lysotracker red was excited at $561 \mathrm{~nm}$ and measured at up to $580 \mathrm{~nm}$. The representative images show the typical regions chosen for the analysis in each case. Several regions from neurons and astrocytes, as well as from the extracellular media, were analysed and the intensity averaged for each type of region.

All data presented were obtained from at least five coverslips and two different cell preparations. The numbers of cells analysed in each experiment are indicated in the text.

In vivo experiments. Experiments were performed on 12 male Sprague-Dawley rats $(300-340 \mathrm{~g})$ and carried out in accordance with the UK Animals (Scientific Procedures) Act, 1986. The rats were anaesthetized with urethane $\left(1.6 \mathrm{~g} \mathrm{~kg}^{-1}\right.$, intraperitoneally). Adequate anaesthesia was ensured by maintaining stable levels of arterial blood pressure, heart and central respiratory rate. The femoral artery and vein were cannulated for measurement of arterial blood pressure and administration of anaesthetic, respectively. The trachea was cannulated, the animal was vagotomized and ventilated with a mixture of 50\% oxygen and 50\% nitrogen using a positive pressure ventilator (Harvard rodent ventilator, model 683) with a tidal volume of $\sim 2 \mathrm{ml}$ and a ventilator frequency similar to spontaneous frequency $(\sim 60$ strokes per $\mathrm{min})$. The animal was then injected with gallamine triethiodide (Flaxedil, $40 \mathrm{mg} \mathrm{kg}^{-1}$, intravenously; then $10 \mathrm{mg} \mathrm{kg}^{-1} \mathrm{~h}^{-1}$, intravenously) and was placed in a stereotaxic frame. The ventral surface of the brainstem was exposed as described previously ${ }^{14,23,24}$. Activities of the phrenic and renal nerves were recorded as indicators of central respiratory and sympathetic drives. Renal sympathetic nerve activity was integrated and smoothed with a time constant of $10 \mathrm{~s}$ (Spike 2 software, Cambridge Electronic Design Ltd, Cambridge, UK). The body temperature was maintained with a servo-controlled heating pad at $37.0 \pm 0.2^{\circ} \mathrm{C}$. PolyP ( $50 \mu \mathrm{M}$ in saline) was applied to the exposed ventral surface of the brainstem and left on for the duration of the experiment. The effect of this treatment on the arterial blood pressure, heart rate, central respiratory and sympathetic drives was determined. PolyP-evoked changes in mean level of sympathetic activity were determined after normalization of renal sympathetic nerve activity with respect to both resting baseline level (100\%) and complete absence of discharges ( $0 \%$ ) following administration of a ganglionic blocker hexamethonium ( $20 \mathrm{mg}$; intravenously) at the end of the experiment. To determine whether $\mathrm{P} 2$ receptor activation mediates polyP effects on cardiorespiratory activity, MRS2279 $(50 \mu \mathrm{M})$ or PPADS $(100 \mu \mathrm{M})$ were applied to the ventral surface of the brainstem $5 \mathrm{~min}$ before polyP administration.

Statistical analysis. Statistical analysis was performed with the aid of Origin 8 (Microcal Software Inc., Northampton, MA, USA) software. Group data were compared using analysis of variance followed by the Tukey-Kramer's post hoc test (for comparisons among three or more experimental groups) or Student's $t$-test, as appropriate. Data are presented as means \pm s.e.m. Differences at $P<0.05$ were considered to be significant.

\section{References}

1. Kumble, K. D. \& Kornberg, A. Inorganic polyphosphate in mammalian cells and tissues. J. Biol. Chem. 270, 5818-5822 (1995).

2. Gabel, N. W. \& Thomas, V. Evidence for the occurrence and distribution of inorganic polyphosphates in vertebrate tissues. J. Neurochem. 18, 1229-1242 (1971).

3. Pavlov, E. et al. Inorganic polyphosphate and energy metabolism in mammalian cells. J. Biol. Chem. 285, 9420-9428 (2010).

4. Abramov, A. Y. et al. Targeted polyphosphatase expression alters mitochondrial metabolism and inhibits calcium-dependent cell death. Proc. Natl Acad. Sci. USA 104, 18091-18096 (2007).

5. Muller, F. et al. Platelet polyphosphates are proinflammatory and procoagulant mediators in vivo. Cell 139, 1143-1156 (2009).

6. Kim, D. \& Cavanaugh, E. J. Requirement of a soluble intracellular factor for activation of transient receptor potential A1 by pungent chemicals: role of inorganic polyphosphates. J. Neurosci. 27, 6500-6509 (2007).

7. Zakharian, E., Thyagarajan, B., French, R. J., Pavlov, E. \& Rohacs, T. Inorganic polyphosphate modulates TRPM8 channels. PLoS One 4, e5404 (2009).

8. Harper, M. T. \& Poole, A. W. Protein kinase Ctheta negatively regulates storeindependent $\mathrm{Ca} 2+$ entry and phosphatidylserine exposure downstream of glycoprotein VI in platelets. J. Biol. Chem. 285, 19865-19873 (2010).

9. Vieira, R. P. et al. Purinergic receptor type 6 contributes to airway inflammation and remodeling in experimental allergic airway inflammation. Am. J. Respir. Crit. Care Med. 184, 215-223 (2011).

10. Bintig, W. et al. Purine receptors and $\mathrm{Ca}(2+)$ signalling in the human bloodbrain barrier endothelial cell line hCMEC/D3. Purinergic Signal. 8, 71-80 (2012).

11. Aschar-Sobbi, R. et al. High sensitivity, quantitative measurements of polyphosphate using a new DAPI-based approach. J. Fluoresc. 18, 859-866 (2008).

12. Pisoni, R. L. \& Lindley, E. R. Incorporation of [32P]orthophosphate into long chains of inorganic polyphosphate within lysosomes of human fibroblasts. J. Biol. Chem. 267, 3626-3631 (1992).

13. Liu, T. et al. Calcium triggers exocytosis from two types of organelles in a single astrocyte. J. Neurosci. 31, 10593-10601 (2011).

14. Gourine, A. V. et al. Astrocytes control breathing through $\mathrm{pH}$-dependent release of ATP. Science 329, 571-575 (2010).

15. Gourine, A. V., Llaudet, E., Dale, N. \& Spyer, K. M. ATP is a mediator of chemosensory transduction in the central nervous system. Nature 436, 108-111 (2005).

16. Burnstock, G. Purinergic signalling and disorders of the central nervous system. Nat. Rev. Drug Discov. 7, 575-590 (2008)

17. Patel, K. et al. Activity of diadenosine polyphosphates at P2Y receptors stably expressed in 1321N1 cells. Eur. J. Pharmacol. 430, 203-210 (2001).

18. Hiramoto, T., Nemoto, W., Kikuchi, T. \& Fujita, N. Construction of hypothetical three-dimensional structure of P2Y1 receptor based on Fourier transform analysis. J. Protein Chem. 21, 537-545 (2002).

19. Gucek, A., Vardjan, N. \& Zorec, R. Exocytosis in astrocytes: transmitter release and membrane signal regulation. Neurochem. Res. 37, 2351-2363 (2012).

20. Vaarmann, A., Gandhi, S., Gourine, A. V. \& Abramov, A. Y. Novel pathway for an old neurotransmitter: dopamine-induced neuronal calcium signalling via receptor-independent mechanisms. Cell Calcium 48, 176-182 (2010).

21. Zufferey, R., Nagy, D., Mandel, R. J., Naldini, L. \& Trono, D. Multiply attenuated lentiviral vector achieves efficient gene delivery in vivo. Nat. Biotechnol. 15, 871-875 (1997).

22. Gandhi, S. et al. PINK1-associated Parkinson's disease is caused by neuronal vulnerability to calcium-induced cell death. Mol. Cell 33, 627-638 (2009).

23. Marina, N. et al. Essential role of Phox2b-expressing ventrolateral brainstem neurons in the chemosensory control of inspiration and expiration. J. Neurosci. 30, 12466-12473 (2010).

24. Marina, N. et al. Control of sympathetic vasomotor tone by catecholaminergic $\mathrm{C} 1$ neurones of the rostral ventrolateral medulla oblongata. Cardiovasc. Res. 91, 703-710 (2011).

\section{Acknowledgements}

A.V.G. is a Wellcome Trust Senior Research Fellow; A.Y.A. is a Parkinson's UK Senior Research Fellow. The work was supported by the Wellcome Trust, M.R.C. Parkinson's Consortium Grant and the Leverhulme Trust. We thank Professor David Attwell for critical review of the manuscript. 


\section{Author contributions}

K.M.H., A.Y.A. and A.V.G. designed and performed the experiments, and wrote the manuscript. A.Y.A. directed the in vitro experiments and A.V.G. directed the in vivo experiments. N.M. and A.Y.B. performed the experiments, and N.W.W. helped to prepare the manuscript.

\section{Additional information}

Supplementary Information accompanies this paper at http://www.nature.com/ naturecommunications

Competing financial interests: The authors declare no competing financial interests.
Reprints and permission information is available online at http://npg.nature.com/ reprintsandpermissions/

How to cite this article: Holmström, K. M. et al. Signalling properties of inorganic polyphosphate in the mammalian brain. Nat. Commun. 4:1362 doi: 10.1038/ ncomms2364 (2013).

(c) (i) (2) This work is licensed under a Creative Commons AttributionSA NonCommercial-ShareAlike 3.0 Unported License. To view a copy of this license, visit http://creativecommons.org/licenses/by-nc-sa/3.0/ 